\title{
Extensive pneumatisation of the sphenoid bone: anatomical investigation of the recesses of the sphenoid sinuses and their clinical importance
}

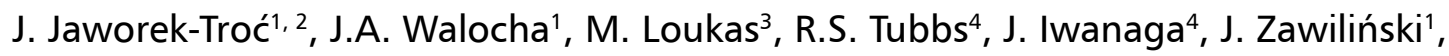 \\ K. Brzegowy' ${ }^{1}$, J.J. Zarzecki ${ }^{5}$, A. Curlej-Wądrzyk6 ${ }^{6}$, E. Kucharska7, F. Burdan ${ }^{8}$, P. Janda ${ }^{1}$, \\ M.P. Zarzecki ${ }^{1}$ \\ ${ }^{1}$ Department of Anatomy, Jagiellonian University Medical College, Krakow, Poland \\ ${ }^{2}$ Department of Radiology, Jagiellonian University Medical College, Krakow, Poland \\ ${ }^{3}$ Department of Anatomical Sciences, St. George's University, Grenada \\ ${ }^{4}$ Department of Neurosurgery, Tulane University School of Medicine, New Orleans, United States \\ ${ }^{5}$ Medical University of Silesia, Katowice, Poland \\ ${ }^{6}$ Department of Integrated Dentistry, Dental Institute, Jagiellonian University Medical College, Krakow, Poland \\ 'Department of Gerontology, Geriatrics and Social Work, Jesuit University Ignatianum, Krakow, Poland \\ ${ }^{8}$ Human Anatomy Department, Medical University, Lublin, Poland
}

[Received: 31 July 2021; Accepted: 20 September 2020; Early publication date: 24 September 2020]

Background: There is a great variance between the extents of pneumatisation of the sphenoid sinuses that can reach beyond the body of the sphenoid bone. The purpose of this study was to find the prevalence of the recesses of the sphenoid sinuses in Polish adult population.

Materials and methods: Two hundred ninety-six computed tomography (CT) scans of patients who did not present any pathology in the sphenoid sinuses were evaluated in this retrospective analysis. Spiral CT scanner (Siemens Somatom Sensation 16) was used to glean the medical images. Standard scan procedure was applied, with Siemens CARE Dose 4D option enabled. No contrast medium was administered. Results: In the majority of the patients (93.92\%), the pneumatisation of the sphenoid sinuses expanded beyond the body of the sphenoid bone; hence, there were recesses of the sinuses present. The most common variant was the presence of two recesses - 12.84\% of cases. The prevalence of all the 17 recesses was only $0.34 \%$. Amongst the uneven recesses present, the sphenoidal rostrum's recess (61.15\% of the patients) and the inferior clinoid recess (56.42\%) were the most common. Amongst the even recesses present, the lateral recess was prevalent in the majority $(65.88 \%)$, whereas the posterior clinoid process' recess was the least common (9.8\%).

Conclusions: Presence of the recesses might facilitate access to the cranial fossae; hence, comprehensive evaluation of the sphenoid sinuses is of immense importance in order to avoid unnecessary drills through the hard bone, which could potentially damage the nearby neurovascular structures. (Folia Morphol 2021; 80, 4: 935-946)

Key words: sphenoid sinus, recess, anatomy, otorhinolaryngology, neurosurgery 


\section{INTRODUCTION}

The body of the sphenoid bone contains pneumatic spaces filled with air, lined with mucous membrane, known as the sphenoid sinuses. Usually denoted as right and left, separated by the main septum, they are known to have a vastly varied morphology. Some of the most notable discrepancies between them include: their dimensions, relation to the surrounding neurovascular structures, the number of septa present, and the degree to which they are aerated (pneumatised) [20-23]. Henceforth, it is extremely difficult to assign one variation as a "normal anatomical variant" of the sphenoid sinuses due to the scarcity of unequivocal patterns found [21].

Previous studies reported that the sphenoid sinuses begin to develop approximately around the $3^{\text {rd }}-4^{\text {th }}$ month of gestation, as a result of bilateral intussusception of the nasal mucosa in the direction of the sphenoid bone $[13,52]$. It is possible to find the yet not pneumatised sinuses in the newborn which at that period of their development form small cavities within the sphenoid body [9]. This primary process of aeration is a form of continuation of the sphenoethmoidal recess [30]. The proper pneumatisation of the sphenoid sinuses commences postnatally (around the age of 3-4), but the exact moment of termination of this process is not known (approximately 12-16 years of age), usually with completely aerated sinuses in the third decade of life [55]. This secondary process of aeration involves the growth of connective tissue into the viscerocranium [30].

However, quite often the pneumatisation of the sphenoid sinuses reaches beyond the body of the sphenoid bone, forming recesses. It might involve other parts of the sphenoid bone (e.g. lesser and greater wings, pterygoid process) and/or neighbouring bones (e.g. vomer, palatine bones) [21]. As such they become a matter of clinical importance during invasive procedures carried out within the lumen of the sinuses. For example, presence of the anterior clinoid process pneumatisation (the posterolateral recess) might lead to pneumocephalus or rhinorrhoea [51], but its presence is also useful while accessing aneurysms of the paraclinoid and supraclinoid parts of the internal carotid artery or central nervous system tumours in that region [2].

Preoperative comprehensive evaluation of the sphenoid sinus and its neighbouring neurovascular structures is of immense importance in order to perform a safe procedure and diminish the risk of iatrogenic complications $[1,14,15,25,27,28,34$, $35,37,40,48]$. Computed tomography (CT) scan is regarded as one of the most accurate methods of gleaning the medical images of the paranasal sinuses, as it allows pinpointing a clear-cut representation of the osseous structures and identify anatomical variations. Most certainly it provides more accurate information regarding the variant morphology of the sphenoid sinuses than the data provided from cadaveric dissections [6].

Endoscopic approaches are said to be the golden standard for the treatment of cerebrospinal fluid (CSF) leakage [3] and facilitate access to various pathologies found "between the frontal sinus and the upper border of lower $1 / 3$ of the clivus (dens) in the sagittal plane or those between the 2 orbits superiorly and jugular foramens inferiorly in the paramedian plane" [50]. The minimally invasive endoscopic techniques allowed medical professionals to decrease the number of classical extensive surgical interventions performed in this region.

The primary aim of this study was to present the up-to-date prevalence of the recesses of the sphenoid sinuses in Polish adult patients by the means of CT imaging in order to aid physicians in carrying out invasive endoscopic procedures in that region. The secondary outcome of the study was the subgroup analysis of females and males so as to evaluate whether there are any statistically significant differences between the presence of the particular recesses and gender. To the best knowledge of the authors this is the first study that has comprehensively taken into the account the possible impact of patients' sex upon the prevalence of all the possible sphenoid sinus' recesses.

\section{MATERIALS AND METHODS}

The researchers had access to a total of 359 medical images of patients referred to the Department of Medical Imaging of the University Hospital in Krakow to undergo a CT scan. In order to participate in this study, the patients had to be over eighteen years old and present no pathologies in the sphenoid sinuses. Patients, who had suffered from a head trauma or had undergone nasal, orbital or cranial basis surgery prior to the research, were not included in the following analysis (63 patients). A total of 296 patients (147 females, 149 males) fulfilled the inclusion criteria and were hence included in this retrospective analysis.

Standard procedure was applied with Siemens CARE Dose 4D option enabled while obtaining the 
CT scans via spiral CT scanner Siemens Somatom Sensation 16. Contrast medium was not administered to any of the patients. Multiplans reconstruction tool was used in order to reconstruct the images in the coronal and sagittal planes, after the CT images in the axial planes were gleaned in the first instance. Diagnostic station Siemens Volume Wizard was used to evaluate the medical imaging data. Seven researchers evaluated the obtained data (J.J.T., J.A.W., M.L., J.Z., K.B., J.J.Z., M.P.Z.).

The analysis of the obtained images involved the presence of the sphenoid sinuses' recesses (depending on the direction of the pneumatisation), as adapted from the classification of the previous authors $[8,10,38]$ :

1. The median pneumatisation:

- in the anterior direction:

- the sphenoidal rostrum's recess (in the direction of the sphenoidal rostrum),

- the septal recess (in the direction of the main septum of the sphenoid sinuses),

- the vomeral recess (in the direction of the vomer);

- in the posterior direction:

- the superior clinoid recess (in the dorsal direction of the sella turcica; for this recess, presence of the pneumatisation of the posterior clinoid process was also taken into account),

- the inferior clinoid recess (in the direction of Blumenbach's clivus).

2. The lateral pneumatisation:

- the anterolateral recess (in the direction of the lesser wing of the sphenoid bone, superior to the optic canal);

- the posterolateral recess (in the direction of the lesser wing of the sphenoid bone, comprising the anterior clinoid processes);

- the lateral recess (in the direction of the greater wing of the sphenoid bone if the pneumatisation crossed the conventional line between the foramen rotundum and the pterygoid/Vidian canal);

- the pterygoid recess (in the direction of the pterygoid process of the sphenoid bone);

- the palatine recess (in the direction of the palatine bone).

\section{Ethical approval}

All procedures performed in studies involving human participants were in accordance with the ethical standards of the institutional and/or national research committee and with the 1964 Helsinki declaration and its later amendments or comparable ethical standards. For this type of study formal consent is not required.

\section{Statistical analysis}

Statistical analysis in this study was conducted with STATISTICA version 13.3 by TIBCO Software Inc ${ }^{\circledR}$. $\mathrm{Chi}^{2}$ test, Mann-Whitney's test and Fisher's exact test were used to detect between-gender differences in prevalences of specific recesses. A statistically significant value of $p<0.05$ was chosen for all the results.

\section{RESULTS}

In the majority of the patients included in the study (278 - 136 females, 142 males), the pneumatisation of the sphenoid sinuses reached beyond the body of the sphenoid bone, hence there were recesses of the sinuses present. Only in 18 patients (11 females, 7 males) the recesses did not develop. Presence of two recesses was the most common variant - found in 38 patients ( 15 females, 23 males); sporadically there were more than ten recesses present, whereas presence of all the 17 recesses was noted only in one patient. The distributions of the prevalence of the recesses differed significantly between males and females ( $p=0.012$, Mann-Whitney's test). The total number of all of the recesses found is collected in Table 1.

Amongst the uneven recesses, the sphenoidal rostrum's recess was prevalent the most often (in 181 patients -80 females, 101 males), but the inferior clinoid recess was also present in the majority of patients (167 - 71 females, 96 males). The pneumatisation of the main septum was the least common (noted only in 26 patients -8 females, 18 males). Amongst the even recesses, the lateral recess was prevalent the most often (in 195 patients - 97 females, 98 males), whereas the rarest variant was the presence of the posterior clinoid process' recess (only in 29 patients -4 females, 25 males).

There was a statistically significant difference between the proportions of females and males with the presence of the sphenoidal rostrum's recess $\left(p=0.018, \chi^{2}\right.$ test), the septal recess $(p=0.045$, $\chi^{2}$ test), the inferior clinoid recess $\left(p=0.005, \chi^{2}\right.$ test), and the superior clinoid recess ( $p=0.045, \chi^{2}$ test). No statistically significant difference was found between the proportion of females and males with the presence of the vomeral recess ( $p=0.639, \chi^{2}$ test) (Table 2 ). 
Table 1. The prevalence of the sphenoid sinuses' recesses the number of the recesses

\begin{tabular}{lcccccc}
\hline $\begin{array}{l}\text { The number of } \\
\text { the recesses }\end{array}$ & $\mathbf{F}$ & $\mathbf{F} \%$ & $\mathbf{M}$ & $\mathbf{M} \%$ & $\mathbf{F}+\mathbf{M}$ & $\mathbf{F}+\mathbf{M} \%$ \\
\hline 0 & 11 & $7.48 \%$ & 7 & $4.7 \%$ & 18 & $6.08 \%$ \\
1 & 12 & $8.16 \%$ & 11 & $7.38 \%$ & 23 & $7.77 \%$ \\
2 & 15 & $10.2 \%$ & 23 & $15.44 \%$ & 38 & $12.84 \%$ \\
3 & 21 & $14.29 \%$ & 7 & $4.7 \%$ & 28 & $9.46 \%$ \\
4 & 17 & $11.56 \%$ & 12 & $8.05 \%$ & 29 & $9.8 \%$ \\
5 & 10 & $6.8 \%$ & 8 & $5.37 \%$ & 18 & $6.08 \%$ \\
6 & 17 & $11.56 \%$ & 11 & $7.38 \%$ & 28 & $9.46 \%$ \\
7 & 9 & $6.12 \%$ & 12 & $8.05 \%$ & 21 & $7.09 \%$ \\
8 & 12 & $8.16 \%$ & 17 & $11.41 \%$ & 29 & $9.8 \%$ \\
9 & 14 & $9.52 \%$ & 11 & $7.38 \%$ & 25 & $8.45 \%$ \\
10 & 4 & $2.72 \%$ & 9 & $6.04 \%$ & 13 & $4.39 \%$ \\
11 & 2 & $1.36 \%$ & 7 & $4.7 \%$ & 9 & $3.04 \%$ \\
12 & 1 & $0.68 \%$ & 8 & $5.37 \%$ & 9 & $3.04 \%$ \\
13 & 1 & $0.68 \%$ & 2 & $1.34 \%$ & 3 & $1.01 \%$ \\
14 & 1 & $0.68 \%$ & 3 & $2.01 \%$ & 4 & $1.35 \%$ \\
15 & 0 & $0 \%$ & 0 & $0 \%$ & 0 & $0 \%$ \\
16 & 0 & $0 \%$ & 0 & $0 \%$ & 0 & $0 \%$ \\
17 & 0 & $0 \%$ & 1 & $0.67 \%$ & 1 & $0.34 \%$ \\
\hline
\end{tabular}

$\mathrm{F}$ - females; $\mathrm{F} \%$ - the percentage of females; $\mathrm{M}$ - males; $\mathrm{M} \%$ - the percentage of males

Table 2. The prevalence of the uneven recesses in the sphenoid sinuses - the types of the recesses

\begin{tabular}{lcccccc}
\hline & $\mathbf{F}$ & $\mathbf{F} \%$ & $\mathbf{M}$ & $\mathbf{M} \%$ & $\mathbf{F}+\mathbf{M}$ & $\mathbf{F}+\mathbf{M} \%$ \\
\hline $\begin{array}{l}\text { Sphenoidal } \\
\text { rostrum's }\end{array}$ & 80 & $54.42 \%$ & 101 & $67.79 \%$ & 181 & $61.15 \%$ \\
Septal & 8 & $5.44 \%$ & 18 & $12.08 \%$ & 26 & $8.78 \%$ \\
Vomeral & 39 & $26.53 \%$ & 36 & $24.16 \%$ & 75 & $25.34 \%$ \\
Inferior clinoid & 71 & $48.3 \%$ & 96 & $64.43 \%$ & 167 & $56.42 \%$ \\
Superior clinoid & 42 & $28.57 \%$ & 59 & $39.6 \%$ & 101 & $34.12 \%$ \\
\hline
\end{tabular}

$\mathrm{F}$ - females; F\% - the percentage of females; $\mathrm{M}$ - males; $\mathrm{M} \%$ - the percentage of males

Table 3. The prevalence of the even sphenoid sinuses' recesses - the types of the recesses

\begin{tabular}{lcccccc}
\hline & $\mathbf{F}$ & $\mathbf{F} \%$ & $\mathbf{M}$ & $\mathbf{M} \%$ & $\mathbf{F}+\mathbf{M}$ & $\mathbf{F}+\mathbf{M} \%$ \\
\hline Post. clin. proc. & 4 & $2.72 \%$ & 25 & $16.78 \%$ & 29 & $9.8 \%$ \\
Anterolateral & 29 & $19.73 \%$ & 52 & $34.9 \%$ & 81 & $27.36 \%$ \\
Posterolateral & 40 & $27.21 \%$ & 55 & $36.91 \%$ & 95 & $32.09 \%$ \\
Lateral & 97 & $65.99 \%$ & 98 & $65.77 \%$ & 195 & $65.88 \%$ \\
Pterygoid & 59 & $40.14 \%$ & 67 & $44.97 \%$ & 126 & $42.57 \%$ \\
Palatine & 72 & $48.98 \%$ & 70 & $46.98 \%$ & 142 & $47.97 \%$ \\
\hline
\end{tabular}

Post. clin. proc. — posterior clinoid process' recess; $F$ - females; $F \%$ - the percentage of females; $\mathrm{M}$ - males, $\mathrm{M} \%$ - the percentage of females
There was a statistically significant difference between the proportions of females and males with the presence of the posterior clinoid process' recess $\left(p<0.001, \chi^{2}\right.$ test), and the anterolateral recess $\left(p=0.003, \chi^{2}\right.$ test). Notwithstanding, no statistically significant difference was found between the proportion of females and males with the presence of the posterolateral recess $\left(p=0.074, \chi^{2}\right.$ test), the lateral recess $(p=0.969, \chi$ test $)$, the pterygoid recess ( $p=0.401, \chi^{2}$ test), and the palatine recess ( $p=0.731, \chi^{2}$ test) (Table 3$)$.

A statistically significant difference was found between the proportions of females and males with the presence of the posterior clinoid process' recess (PCP) bilaterally $(R+L)\left(p=0.011, \chi^{2}\right.$ test), the PCP unilaterally $(R / L)\left(p=0.002, \chi^{2}\right.$ test), the anterolateral recess $(A-L) R+L\left(p<0.001, \chi^{2}\right.$ test), the posterolateral recess $(P-L) R / L\left(p<0.001, \chi^{2}\right.$ test), the $P-L R / L$ $\left(p=0.034, \chi^{2}\right.$ test), and the lateral recess $(\mathrm{La}) \mathrm{R} / \mathrm{L}$ $\left(p=0.003, \chi^{2}\right.$ test). Nonetheless, no statistically significant differences were found between the proportions of females and males with the presence of the A-L $R / L(p=0.173$, Fischer's exact test), the P-L $R+L$ $\left(p=0.910, \chi^{2}\right.$ test $)$, the La $R+L\left(p=0.621, \chi^{2}\right.$ test), the pterygoid recess $(P) R+L\left(p=0.182, \chi^{2}\right.$ test), the $P R / L\left(p=0.728, \chi^{2}\right.$ test), the palatine recess $(P I)$ $\mathrm{R}+\mathrm{L}\left(\mathrm{p}=0.938, \chi^{2}\right.$ test $)$, and the PI R/L $(p=0.719$, $\chi^{2}$ test) (Table 4).

There was a statistically significant difference found between the proportions of males and females with PCP R+L present ( $p=0.011, \chi^{2}$ test), PCP R $\left(p=0.033, \chi^{2}\right.$ test), and A-L $R+L\left(p<0.001, \chi^{2}\right.$ test). In the remaining variants, no statistically significant difference was noted between genders in the prevalences of the respective recesses: $\mathrm{PCP}$ (left unilateral location $-\mathrm{L}$ ) $(p=0.067$, Fischer's exact test), A-L (right unilateral location $-R)\left(p=0.506, \chi^{2}\right.$ test), A-L L $(p=0.229$, $\chi^{2}$ test), P-L R+L ( $p=0.910, \chi^{2}$ test), P-LR $(p=0.051$, $\chi^{2}$ test), P-L L ( $p=0.393, \chi^{2}$ test), La $R+L(p=0.621$, $\chi^{2}$ test), La $R\left(p=0.518, \chi^{2}\right.$ test), La $L(p=0.265$, $\chi^{2}$ test), P R+L ( $p=0.182, \chi^{2}$ test), P R ( $p=0.846$, $\chi^{2}$ test), $P L\left(p=0.574, \chi^{2}\right.$ test), PI $R+L(p=0.939$, $\chi^{2}$ test), PI R ( $p=0.789, \chi^{2}$ test), PI L ( $p=0.821$, $\chi^{2}$ test) (Tables 5 and 6 , Figs. 1-11).

\section{DISCUSSION}

In the majority of patients (93.92\%), the pneumatisation of the sphenoid sinuses reached beyond the body of the sphenoid bone. The most common variant was the presence of two recesses - found 
Table 4. The prevalence of the even sphenoid sinuses' recesses, taking into the account the unilateral and bilateral location the types and location of the recesses

\begin{tabular}{lcccccc}
\hline & $\mathbf{F}$ & $\mathbf{F} \%$ & $\mathbf{M}$ & $\mathbf{M} \%$ & $\mathbf{F}+\mathbf{M}$ & $\mathbf{F}+\mathbf{M} \%$ \\
\hline PCP R+L & 1 & $0.68 \%$ & 9 & $6.04 \%$ & 10 & $3.38 \%$ \\
PCP R/L & 3 & $2.04 \%$ & 16 & $10.74 \%$ & 19 & $6.42 \%$ \\
A-L R+L & 15 & $10.2 \%$ & 44 & $29.53 \%$ & 59 & $19.93 \%$ \\
A-L R/L & 14 & $9.52 \%$ & 8 & $5.37 \%$ & 22 & $7.43 \%$ \\
P-LR+L & 22 & $14.97 \%$ & 23 & $15.44 \%$ & 45 & $15.2 \%$ \\
P-L R/L & 18 & $12.24 \%$ & 32 & $21.48 \%$ & 50 & $16.89 \%$ \\
La R+L & 58 & $39.46 \%$ & 63 & $42.28 \%$ & 121 & $40.88 \%$ \\
La R/L & 39 & $26.53 \%$ & 35 & $23.49 \%$ & 74 & $25 \%$ \\
PR+L & 28 & $19.05 \%$ & 38 & $25.5 \%$ & 66 & $22.3 \%$ \\
P R/L & 31 & $21.09 \%$ & 29 & $19.46 \%$ & 60 & $20.27 \%$ \\
PIR+L & 45 & $30.61 \%$ & 45 & $30.2 \%$ & 90 & $30.41 \%$ \\
PIR/L & 27 & $18.37 \%$ & 25 & $16.78 \%$ & 52 & $17.57 \%$ \\
\hline R L - . & & & & &
\end{tabular}

$\mathrm{R}+\mathrm{L}$ — bilateral location; $\mathrm{R} / \mathrm{L}$ - unilateral location; $\mathrm{PCP}$ — posterior clinoid process' recess; $\mathrm{A}-\mathrm{L}$ - the anterolateral recess; $\mathrm{P}-\mathrm{L}$ - the posterolateral recess; $\mathrm{La}$ - the lateral recess; $\mathrm{P}$ - the pterygoid recess; $\mathrm{PI}$ - the palatine recess; $\mathrm{F}-$ females; $\mathrm{F} \%$ - the percentage of females; $M$ - males; $M \%$ - the percentage of males

Table 5. The prevalence of the even sphenoid sinuses' recesses, taking into the account the unilateral and bilateral location, as well as the right and left sides (for unilateral locations) - the types and the location of the recesses

\begin{tabular}{lcccccc}
\hline & $\mathbf{F}$ & $\mathbf{F} \%$ & $\mathbf{M}$ & $\mathbf{M} \%$ & $\mathbf{F}+\mathbf{M}$ & $\mathbf{F}+\mathbf{M} \%$ \\
\hline PCP R+L & 1 & $0.68 \%$ & 9 & $6.04 \%$ & 10 & $3.38 \%$ \\
PCP R & 2 & $1.36 \%$ & 9 & $6.04 \%$ & 11 & $3.72 \%$ \\
PCPL & 1 & $0.68 \%$ & 7 & $4.7 \%$ & 8 & $2.7 \%$ \\
A-L R+L & 15 & $10.2 \%$ & 44 & $29.53 \%$ & 59 & $19.93 \%$ \\
A-L & 6 & $4.08 \%$ & 4 & $2.68 \%$ & 10 & $3.38 \%$ \\
A-LL & 8 & $5.44 \%$ & 4 & $2.68 \%$ & 12 & $4.05 \%$ \\
P-L + L & 22 & $14.97 \%$ & 23 & $15.44 \%$ & 45 & $15.2 \%$ \\
P-L R & 9 & $6.12 \%$ & 19 & $12.75 \%$ & 28 & $9.46 \%$ \\
P-LL & 9 & $6.12 \%$ & 13 & $8.72 \%$ & 22 & $7.43 \%$ \\
La R+L & 58 & $39.46 \%$ & 63 & $42.28 \%$ & 121 & $40.88 \%$ \\
La R & 9 & $6.12 \%$ & 12 & $8.05 \%$ & 21 & $7.09 \%$ \\
LaL & 30 & $20.41 \%$ & 23 & $15.44 \%$ & 53 & $17.91 \%$ \\
PR+L & 28 & $19.05 \%$ & 38 & $25.5 \%$ & 66 & $22.3 \%$ \\
PR & 10 & $6.8 \%$ & 11 & $7.38 \%$ & 21 & $7.09 \%$ \\
PL & 21 & $14.29 \%$ & 18 & $12.08 \%$ & 39 & $13.18 \%$ \\
PIR+L & 45 & $30.61 \%$ & 45 & $30.2 \%$ & 90 & $30.41 \%$ \\
PIR & 10 & $6.8 \%$ & 9 & $6.04 \%$ & 19 & $6.42 \%$ \\
PIL & 17 & $11.56 \%$ & 16 & $10.74 \%$ & 33 & $11.15 \%$ \\
\hline P & & & & & & \\
\hline
\end{tabular}

$\mathrm{R}+\mathrm{L}$ - bilateral location; $\mathrm{R}$ - right side location; $\mathrm{L}$ — left side location; $\mathrm{PCP}$ — the posterior clinoid process' recess; $\mathrm{A}-\mathrm{L}$ - the anterolateral recess; $\mathrm{P}-\mathrm{L}$ - the posterolateral recess; $\mathrm{La}$ - the lateral recess; $\mathrm{P}$ - the pterygoid recess; $\mathrm{PI}$ — the palatine recess; $\mathrm{F}$ - females; $\mathrm{F} \%$ - the percentage of females; $\mathrm{M}$ - males; $\mathrm{M} \%$ - the percentage of males
Table 6. The prevalence of the even and uneven sphenoid sinuses' recesses, cumulative data

\begin{tabular}{lcccccc}
\hline & $\mathbf{F}$ & $\mathbf{F} \%$ & $\mathbf{M}$ & $\mathbf{M} \%$ & $\mathbf{F}+\mathbf{M}$ & $\mathbf{F}+\mathbf{M} \%$ \\
\hline $\begin{array}{l}\text { Sphenoidal } \\
\text { rostrum's }\end{array}$ & 80 & $54.42 \%$ & 101 & $67.79 \%$ & 181 & $61.15 \%$ \\
Septal & 8 & $5.44 \%$ & 18 & $12.08 \%$ & 26 & $8.78 \%$ \\
Vomeral & 39 & $26.53 \%$ & 36 & $24.16 \%$ & 75 & $25.34 \%$ \\
Inferior clinoid & 71 & $48.3 \%$ & 96 & $64.43 \%$ & 167 & $56.42 \%$ \\
Superior clinoid & 42 & $28.57 \%$ & 59 & $39.6 \%$ & 101 & $34.12 \%$ \\
Pos. clin. proc. & 4 & $2.72 \%$ & 25 & $16.78 \%$ & 29 & $9.8 \%$ \\
Anterolateral & 29 & $19.73 \%$ & 52 & $34.9 \%$ & 81 & $27.36 \%$ \\
Posterolateral & 40 & $27.21 \%$ & 55 & $36.91 \%$ & 95 & $32.09 \%$ \\
Lateral & 97 & $65.99 \%$ & 98 & $65.77 \%$ & 195 & $65.88 \%$ \\
Pterygoid & 59 & $40.14 \%$ & 67 & $44.97 \%$ & 126 & $42.57 \%$ \\
Palatine & 72 & $48.98 \%$ & 70 & $46.98 \%$ & 142 & $47.97 \%$ \\
\hline
\end{tabular}

Post. clin. proc. — posterior clinoid process' recess; $F$ - females; F\% — the percentage of females; $\mathrm{M}$ - males; $\mathrm{M} \%$ - the percentage of males

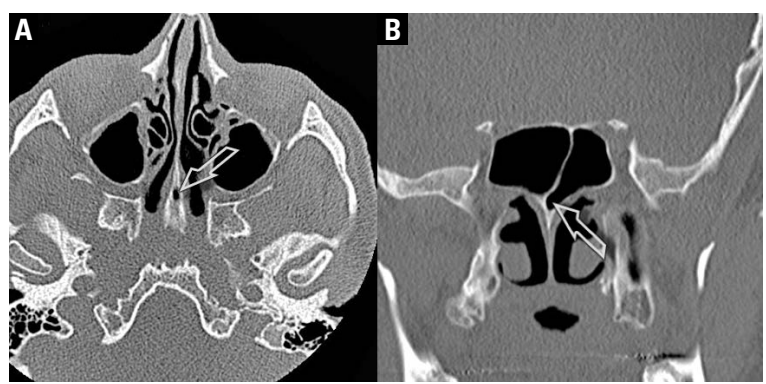

Figure 1. A computed tomography scan of the paranasal sinuses, the sphenoidal rostrum's recess; A. Axial plane; B. Coronal plane.

in $12.84 \%$ of the case, sporadically there were more than ten recesses present, whereas the presence of all the 17 recesses was noticed only in $0.34 \%$ of the patients ( $0.67 \%$ males).

Amongst the uneven recesses, the most common was the sphenoidal rostrum's recess $(61.15 \%)$, but the inferior clinoid recess was also prevalent very often $(56.42 \%)$. The rarest variant found was the pneumatisation of the main septum (8.78\%). Amongst the even recesses, the lateral recess was present in the majority of the patients $(65.88 \%)$, whereas the rarest was the posterior clinoid process' recess, found only in $9.8 \%$ of the patients. Table 7 presents the comparison between the results presented in this research and the previous studies $[2,4,7,8,10-13,16-19$, $24,27,31-33,36,39,45,46,49,56]$. 


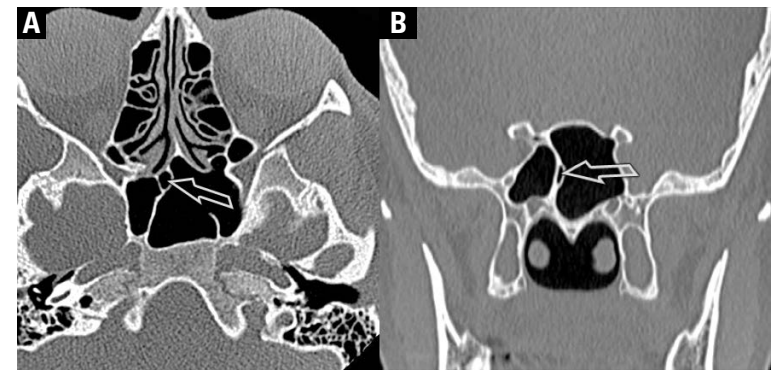

Figure 2. A computed tomography scan of the paranasal sinuses, the septal recess; A. Axial plane; B. Coronal plane.

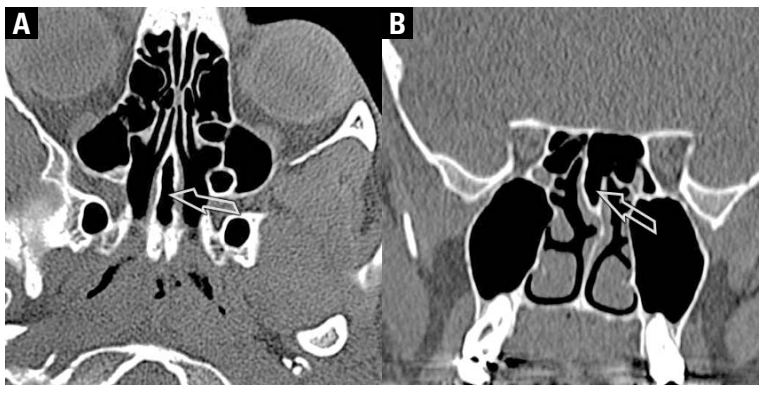

Figure 3. A computed tomography scan of the paranasal sinuses, the vomeral recess; A. Axial plane; B. Coronal plane.

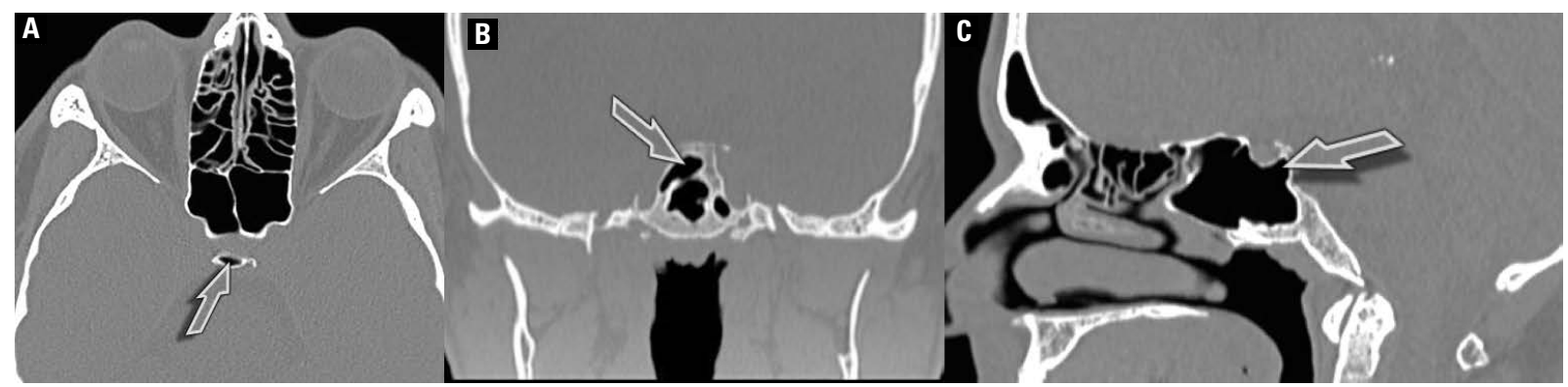

Figure 4. A computed tomography scan of the paranasal sinuses, the superior clinoid recess; A. Axial plane; B. Coronal plane; C. Sagittal plane.

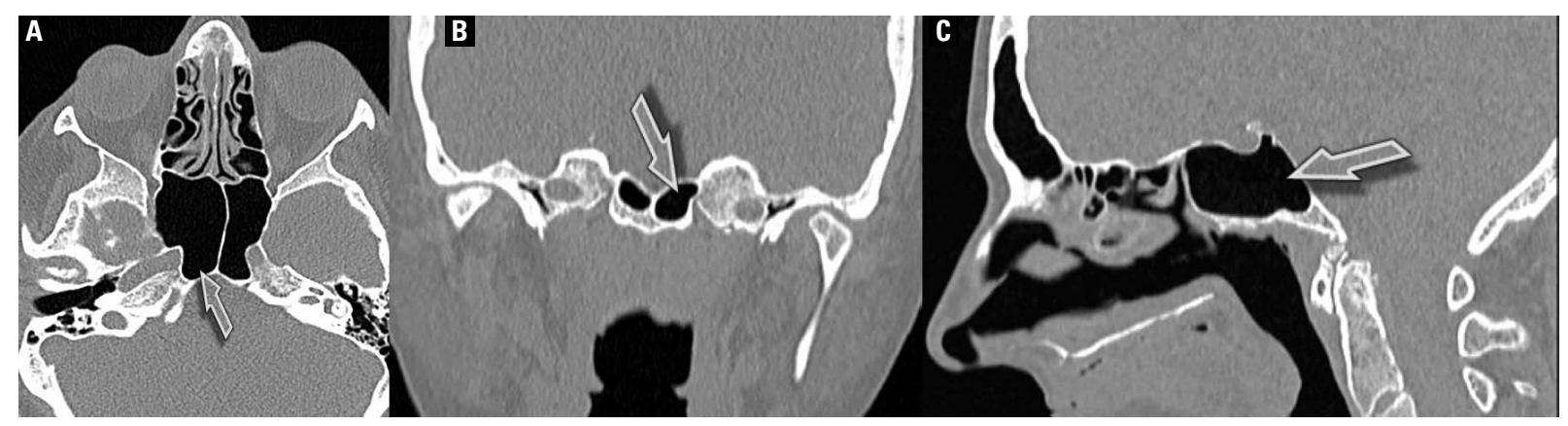

Figure 5. A computed tomography scan of the paranasal sinuses, the inferior clinoid recess; A. Axial plane; B. Coronal plane; C. Sagittal plane.

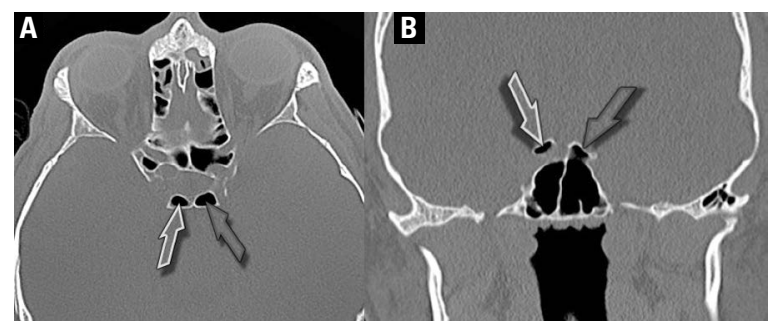

Figure 6. A computed tomography scan of the paranasal sinuses, the superior clinoid recess. Bilateral pneumatisation of the posterior clinoid process; A. Axial plane; B. Coronal plane.

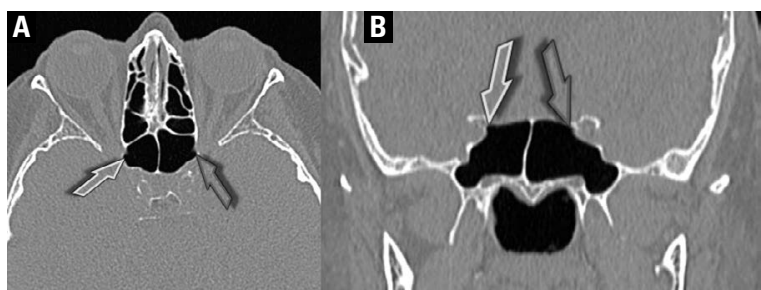

Figure 7. A computed tomography scan of the paranasal sinuses, the bilateral anterolateral recess; A. Axial plane; B. Coronal plane. 


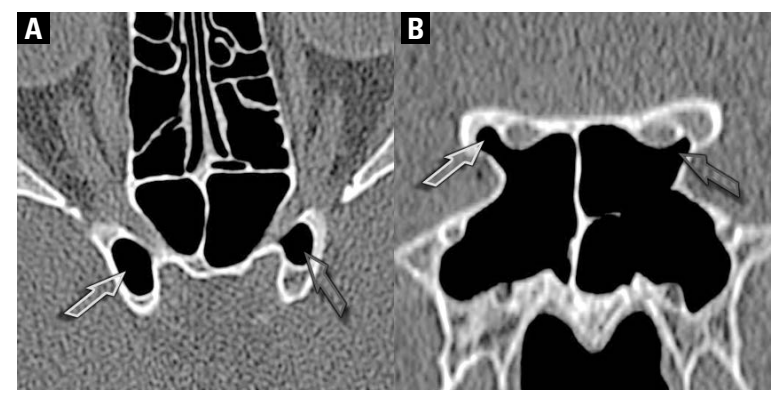

Figure 8. A computed tomography scan of the paranasal sinuses, the bilateral posterolateral recess; A. Axial plane; B. Coronal plane.

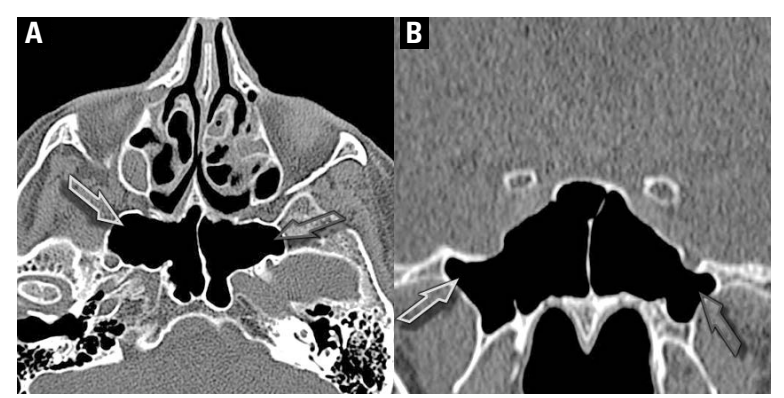

Figure 9. A computed tomography scan of the paranasal sinuses, the bilateral lateral recess; A. Axial plane; B. Coronal plane.

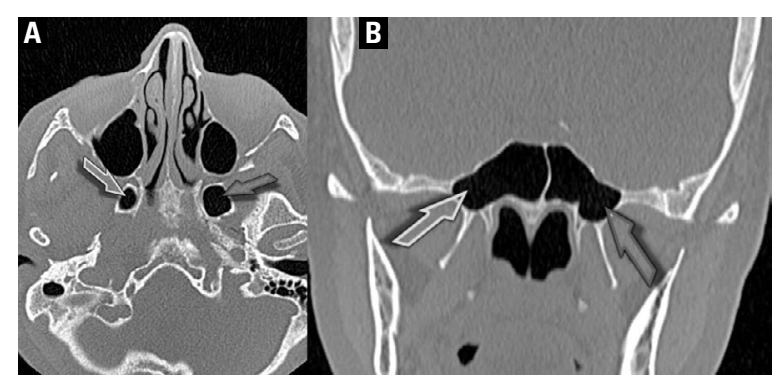

Figure 10. A computed tomography scan of the paranasal sinuses, the bilateral pterygoid recess; A. Axial plane; B. Coronal plane.

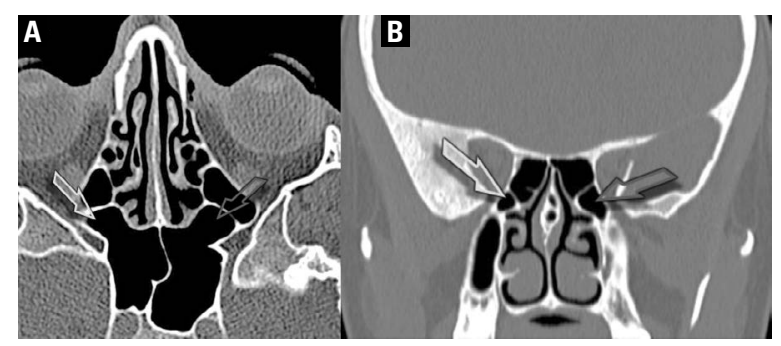

Figure 11. A computed tomography scan of the paranasal sinuses, the bilateral palatine recess; A. Axial plane; B. Coronal plane.

Lower prevalence of the superior clinoid recess was given by Hamid et al. [16] (13.51\%), but higher for the anterolateral recess (described as the pneu- matisation of the sphenoidal plane) (36.49\%). It may be associated with the patient inclusion criteria (all the patients had a pituitary adenoma) and the ethnic group studied (the Egyptians). Lupascu et al. [33] provided a similar data for the presence of the pterygoid recess (evaluating it as $33 \%$ ), but the prevalence of the posterolateral recess in their research is worth noting - only $10 \%$. There is a discrepancy between the age criterions - their lower boundary was 15 years of age, whereas in the present study the lower boundary was 18 years of age.

Awadalla et al. [4] provided a different set of results. In the research group A (anatomical study of 25 skulls), they found the following frequencies of the sinuses' pneumatisation: the sphenoid body type $(36 \%)$, the lateral type including the distinction between the greater wing type $(12 \%)$, the pterygoid process type $(16 \%)$, the clival recess $(12 \%)$, the dorsal type $(4 \%)$, the subdorsal type $(4 \%)$ and the lesser wing type $(12 \%)$. In the group B (radiological study: $\mathrm{CT} /$ magnetic resonance imaging [MRI] scans of 364 patients), Awadalla et al. [4] provided only the pneumatisation of the sphenoid body type $(20 \%)$ and the lateral types: the greater wing type $(5 \%)$ and the pterygoid process type (4\%). Additionally, they found the prevalence of the full bilateral lateral pneumatisation (the bilateral pneumatisation of the greater wing and the pterygoid process) at 3.6\% [4]. The dissimilar results may possibly be put down to the ethnicity of the patients (the Egyptians), the study method with which the sphenoid sinuses were researched (anatomical study of the skulls or MRI scans), the number of the skulls evaluated in the group A (25; from this group only skulls with the sellar type of pneumatisation were chosen and evaluated -22 skulls) and the evaluation criteria of the types of pneumatisation (not reported in the work).

Definitely lower prevalence of the pneumatisation of the anterior clinoid process (the posterolateral recess) was noted by Abuzayed et al. [2], who estimated it as $9.6 \%$ ( $2.1 \%$ on the right side, $1.7 \%$ on the left side, $5.7 \%$ bilateral). The aforementioned scientists divided the degree of pneumatisation into three types: the type I - less than $50 \%$ of the recesses was pneumatised $(6.6 \%)$, the type II - more than $50 \%$ of the recesses was pneumatised, but they were not completely pneumatised (3.5\%) and the type III — the completely pneumatised recesses (2.5\%) [2].

Cope stated that the lumen of the sphenoid sinuses extends more often outside the body of the sphe- 
Table 7. The prevalence [\%] of the sphenoid sinuses' recesses - the types of the recesses

\begin{tabular}{|c|c|c|c|c|c|c|c|c|c|c|c|c|}
\hline Author (material and methods) & NR & SR & Sep & V & SC & PCP & IC & $A-L$ & $\mathbf{P}-\mathbf{L}$ & La & $\mathbf{P}$ & PI \\
\hline Ota et al. (72 CT scans) & - & - & - & - & - & - & - & - & 27.7 & - & - & - \\
\hline Heskova et al. (34 CT scans) & - & - & - & - & - & - & - & - & 26.5 & - & - & - \\
\hline Lakshmi et al. (114 CT scans) & - & - & - & - & - & - & - & - & 23.6 & - & - & - \\
\hline Kazkayasi et al. (267 CT scans) & - & - & - & - & - & - & - & - & 17.2 & - & 39.7 & - \\
\hline Lewin et al. (72 CT scans) & - & - & - & - & - & - & - & - & - & 56.94 & - & - \\
\hline Tomovic et al. (170 HRCT) & - & - & - & - & - & - & - & - & 20 & 72.4 & - & - \\
\hline Kajoak et al. (201 CT scans) & - & - & - & - & - & - & - & - & 13.9 & 34.8 & 40.3 & - \\
\hline Hamid et al. (296 CT and MRI scans) & - & - & - & - & 13.51 & - & - & 36.49 & - & - & - & - \\
\hline Lupascu et al. (200 CT scans) & - & - & - & - & - & - & - & - & 10 & - & 33 & - \\
\hline Citardi et al. (64 CT scans of the skulls) & - & - & - & - & - & - & - & - & 23 & - & 38 & - \\
\hline Hewaidi and Omami (300 CT scans) & - & - & - & - & - & - & - & - & 15.3 & 20 & 29 & - \\
\hline Awadalla gr. A (25 skulls, dissection study) & 36 & - & - & - & 8 & - & 12 & - & 12 & 12 & 16 & - \\
\hline Awadalla gr. B (364 CT and/or MRI scans) & 20 & - & - & - & - & - & - & - & - & $5 / 3.6$ & $4 / 3.6$ & - \\
\hline Earwaker (800 CT scans) & - & 9.75 & 15.25 & 7.5 & 4.86 & - & 8.63 & 4.86 & 14 & 30 & 14.25 & - \\
\hline Abuzayed et al. (648 CT scans) & - & - & - & - & - & - & - & - & 9.6 & - & - & - \\
\hline Li et al. (350 CT scans) & - & - & - & - & - & - & - & - & 10 & - & - & - \\
\hline Cope (-) & $?$ & - & - & - & - & - & $?$ & 5 & 5 & 24.66 & - & - \\
\hline $\begin{array}{l}\text { Elwany et al. } 1983 \text { (100 X-rays, } 100 \text { skulls } \\
\text { X-rayed, } 50 \text { skulls — dissection study) }\end{array}$ & - & - & - & - & - & a & 6 & - & a & $b$ & $b$ & - \\
\hline $\begin{array}{l}\text { Elwany et al. } 1999 \text { (93 skulls, endoscopic and } \\
\text { dissection study) }\end{array}$ & - & - & - & - & - & 5.9 & - & - & - & 31.7 & 15.5 & - \\
\hline ELKammash et al. (182 CT and MRI scans) & - & - & - & - & - & - & 21.1 & 6.4 & 7 & 5.1 & 18 & - \\
\hline Stokovic et al. (51 skulls in CBCT) & - & - & - & - & 9 & - & 18 & 62 & - & 12 & 17 & - \\
\hline $\begin{array}{l}\text { Tan and Ong (48 skulls, endoscopic and } \\
\text { dissection study) }\end{array}$ & 77.5 & 77.5 & 77.5 & 77.5 & 77.5 & 77.5 & 77.5 & 77.5 & 77.5 & 77.5 & 77.5 & 77.5 \\
\hline Idowu et al. (60 CT scans) & - & - & - & - & - & - & - & - & - & 0 & - & - \\
\hline Yune et al. (-) & $?$ & $?$ & $?$ & $?$ & $?$ & $?$ & $?$ & $?$ & $?$ & $?$ & $?$ & $?$ \\
\hline Jaworek-Troć et al. (296 CT scans) & 6.08 & 61.15 & 8.78 & 25.34 & 34.12 & 9.8 & 56.42 & 27.36 & 32.09 & 65.88 & 42.57 & 47.97 \\
\hline
\end{tabular}

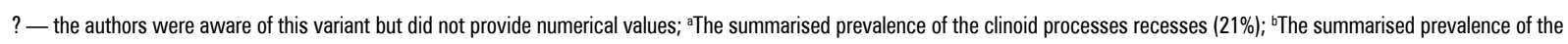
lateral and the pterygoid recesses (15\%); NR — no recesses; SR — the sphenoidal rostrum's recess; Sep — the septal recess; V — the vomeral recess; SC — the superior clinoid recess; PCP — the posterior clinoid process' recess; IC — the inferior clinoid recess; A-L — the anterolateral recess; P-L — the posterolateral recess; La — the lateral recess; $\mathrm{P}$ - the pterygoid recess; $\mathrm{PI}$ — the palatine recess; $\mathrm{CT}$ — computed tomography; CBCT — cone-beam computed tomography; HRCT — high resolution computed tomography; MRI — magnetic resonance imaging

Table 8. The prevalence [\%] of the sphenoid sinuses' recesses - the number of the recesses

\begin{tabular}{lcccccccccccccccccc}
\hline $\begin{array}{l}\text { Author (material and } \\
\text { methods) }\end{array}$ & $\mathbf{0}$ & $\mathbf{1}$ & $\mathbf{2}$ & $\mathbf{3}$ & $\mathbf{4}$ & $\mathbf{5}$ & $\mathbf{6}$ & $\mathbf{7}$ & $\mathbf{8}$ & $\mathbf{9}$ & $\mathbf{1 0}$ & $\mathbf{1 1}$ & $\mathbf{1 2}$ & $\mathbf{1 3}$ & $\mathbf{1 4}$ & $\mathbf{1 5}$ & $\mathbf{1 6}$ & $\mathbf{1 7}$ \\
\hline $\begin{array}{l}\text { Earwaker } \\
\text { (800 CT scans) }\end{array}$ & - & 17.13 & 11.86 & 8.13 & 2.36 & 2.63 & 2.86 & 1.13 & 1.36 & 0.5 & 0.86 & 0.86 & 0.86 & 0.86 & - & - & - & - \\
$\begin{array}{l}\text { Jaworek-Troć et al. } \\
\text { (296 CT scans) }\end{array}$ & 6.08 & 7.77 & 12.84 & 9.46 & 9.8 & 6.08 & 9.46 & 7.09 & 9.8 & 8.45 & 4.39 & 3.04 & 3.04 & 1.01 & 1.35 & 0 & 0 & 0.34 \\
\hline
\end{tabular}

CT - computed tomography

noid bone anteriorly, posteriorly or laterally than it is confined to the body of the sphenoid [8]. He found the lateral recess (extending towards the greater wing of the sphenoid bone) in $24.66 \%$ (292 sinuses studied), but in a few instances (no specific number specified) the pneumatisation reached the pterygoid process of the sphenoid bone [8]. Furthermore, the author mentioned the presence of the very rare posterior recess (in the direction of the Blumenbach's clivus) [8]. 
Idowu et al. [19] noted a completely different set of results - they did not find any lateral recesses after studying 60 CT scans of their patients. The dissimilarity between the data may be associated with the small research group and the Nigerian population studied. Yune et al. [56] noticed that the pneumatisation of the sphenoid sinuses varies from the minimal to relatively big (reaching the anterior or the posterior clinoid processes, the lesser or greater wings of the sphenoid bone or the pterygoid process), but they did not provide the prevalence of the recesses.

Earwaker [10] in the researched material from 800 patients (CT scans of the paranasal sinuses) provided similar frequencies for the two and three recesses present in 1 patient $(11.86 \%$ and $8.13 \%$ respectively). Notwithstanding, other results differ from the data found in the present study - the aforementioned researcher reported a higher presence of a single recess in one patient (17.13\%), but lower prevalence for multiple recesses in 1 patient. The author did not provide the number of the patients in whose sphenoid sinuses there were no recesses present nor there were more than 13 recesses noted (Table 8) [10].

The vomeral recess, when present, poses a risk of a constricted access towards the sphenoidal sinus, as depending on its size it is possible that it would narrow the sphenoethmoidal recess and hinder the way towards the ostium of the sphenoid sinus [5]. Similarly, the septal recess might impede the entrance to the sphenoid sinus via its ostium. In this study, the vomeral recess was present in $25.34 \%$, whereas the septal recess in $8.78 \%$ of the patients.

The posterolateral recess (that comprises the anterior clinoid process) might be a useful variation aiding surgeons during the anterior clinoidectomy by pointing a safe limit during the drilling, if present [2]. As a medical professional reaches these air-filled cells, it warrants a more careful continuation of the surgery due to the closeness of nearby neurovascular structures with vigilance whilst removing the rest of this thin cortical bone [2]. In the proximity of the anterior clinoid process there can be found the following anatomical structures: the oculomotor nerve, the trochlear nerve, the ophthalmic nerve, and the clinoidal segment of the internal carotid artery. We would like to acknowledge Abuzayed et al. [2] in saying that the greater the aeration of the anterior clinoid process, the bigger the safe margin for controlled drilling, but the presence of the posterolateral recess necessitates its later closure after the procedure to diminish the risk of rhinorrhoea and
CSF leakage from that region. Notwithstanding, it can also be an unusual site of development of mucocoele that might compress the nearby neurovascular structures, causing frontal or orbital headaches or signs and symptoms assigned to cranial nerves II to VI [47]. Henceforth it is crucial not to cause the rupture the mucous membrane covering the lumen of the posterolateral recess, so as to diminish the risk of mucocoele [2]. In this study, the posterolateral recess was present in $32.09 \%$, predominantly bilaterally $(15.2 \%$ of the patients studied).

Presence of the lateral recess of the sphenoid sinuses noted preoperatively can be of immense importance, as it facilitates access to the lateral lesions of the cavernous sinus [29]. The size of the access point to the middle cranial fossa through the lateral recess has the following boundaries: inferiorly the Vidian nerve, superiorly the maxillary nerve, and posteriorly the terminal petrous and adjacent segments of the internal carotid artery [53]. Notwithstanding, a surgeon has to drill through the bone of the sphenoid in the proximity of the internal carotid artery when this recess is absent, a difficult task with the narrow endoscopic surgical field [29] that might result in iatrogenic injury to the artery. Moreover, it is probable that an infection of the sphenoid sinus might spread to the cavernous sinus [26], especially when the bone separating them is thinned by the presence of the lateral recess. Furthermore, the lateral recess of the sphenoid sinus is a known point of origin of the CSF leakage, most often of spontaneous nature [54]. Shetty et al. [42] in their retrospective analysis of spontaneous sphenoid CSF leaks have found extensive lateral pneumatisation of the sphenoid sinus in $90 \%$ of their patients compared to $23 \%$ controls. Moreover there are reports noting temporal lobe meningocoeles that herniated through the lateral recess into the sphenoid sinus [41]. Trans-sphenoidal approach towards the lateral recess might be attained with the help of angled endoscopes [50]. In this study, the lateral recess was present in $65.88 \%$ of the patients, predominantly bilaterally (40.88\%).

The inferior clinoid recess might aid in approaching the posterior cranial fossa, especially since the extensive pneumatisation thinners the clivus, making it easier to create the clival window [53]. As a result of the clival aeration, a surgeon can gain access to the space between the dorsum sellae and foramen magnum [53], possibly allowing for biopsy of brainstem lesions or approaching the surrounding CSF 
cisterns. The inferior clinoid recess was present in $56.42 \%$ of the patients studied.

In orthodontics, lateral cephalometric radiographic assessment is a crucial step whilst planning treatment. Sinha et al. [43] have suggested a possible correlation between the dimensions of the sella turcica and its skeletal pattern. Presence of the recesses of the sphenoid sinus might modify the shape and dimensions of the sella, hence their prevalence and impact could be the future direction of research in this area.

The extensive pneumatisation brings the lumen of the sphenoid sinus closer to crucial neurovascular structures, e.g. the maxillary nerve or the Vidian nerve, but fortunately intraoperative fluoroscopic imaging or navigational devices are utilised to curtail the risk of iatrogenic damage to these structures [6]. Some of the most modern techniques of analysing anatomical structures prior to a surgery involve the use of the virtual dissection tables (VDT). Stecco et al. [44] reported that the VDTs helped with stating a more confident diagnosis of perplexing Le Fort fractures (the pterygoid process of the sphenoid bone is involved in all of the types of these fractures), compared to the single use of the standard Picture Archiving and Communication System. Preoperational planning of a trans-sphenoidal surgery with the help of VDT might possibly further assist surgeons in preparation for the procedure in the nearby future, thus enabling better outcomes and quality of the surgery.

\section{CONCLUSIONS}

In the majority of the patients, the pneumatisation of the sphenoid sinuses reached beyond the body of the sphenoid bone, hence there were recesses of the sinuses present. The most common were two recesses of the sphenoid sinuses. The lateral, sphenoidal rostrums and inferior clinoid recesses where the most prevalent types $(65.88 \%, 61.15 \%$ and $56.42 \%$, respectively). Comprehensive preoperational CT evaluation of the sphenoid sinuses should most certainly involve the analysis of presence of the recesses in every case, as they might facilitate access to the cranial fossae that could potentially be less traumatic than drilling through the hard cortical bone of the sphenoid.

\section{Acknowledgements}

The authors would like to express their sincere gratitude to Mr. Jacenty Urbaniak for the technical support.

Conflict of interest: None declared

\section{REFERENCES}

1. Abdullah B, Arasaratnam S, Kumar G, et al. The Sphenoid Sinuses: Computed Tomographic Assessment of Septation, Relationship to the Internal Carotid Arteries, and Sidewall Thickness in the Malaysian Population. Hong Kong J Radiol. 2001; 4(3): 185-188.

2. Abuzayed B, Tanriover N, Biceroglu H, et al. Pneumatization degree of the anterior clinoid process: a new classification. Neurosurg Rev. 2010; 33(3): 367-374, doi: 10.1007/ s10143-010-0255-8, indexed in Pubmed: 20333429.

3. Alexander NS, Chaaban MR, Riley KO, et al. Treatment strategies for lateral sphenoid sinus recess cerebrospinal fluid leaks. Arch Otolaryngol Head Neck Surg. 2012; 138(5): 471-478, doi: 10.1001/archoto.2012.614, indexed in Pubmed: 22652945.

4. Awadalla AM, Hussein Y, ELKammash TH. Anatomical and Radiological Parameters of the Sphenoid Sinus among Egyptians and its Impact on Sellar Region. Egypt J Neurosurg. 2015; 30(1): 1-12.

5. Beale TJ, Madani G, Morley SJ. Imaging of the paranasal sinuses and nasal cavity: normal anatomy and clinically relevant anatomical variants. Semin Ultrasound CT MR. 2009; 30(1): 2-16, doi: 10.1053/j.sult.2008.10.011, indexed in Pubmed: 19388234.

6. Chougule MS, Dixit D. A cross-sectional study of sphenoid sinus through gross and endoscopic dissection in north karnataka, India. J Clin Diagn Res. 2014; 8(4): AC01-AC05, doi: 10.7860/JCDR/2014/7947.4243, indexed in Pubmed: 24959426.

7. Citardi MJ, Gallivan RP, Batra PS, et al. Quantitative computer-aided computed tomography analysis of sphenoid sinus anatomical relationships. Am J Rhinol. 2004; 18(3): 173-178, indexed in Pubmed: 15283492.

8. Cope VZ. The internal structure of the sphenoidal sinus. J Anat. 1917; 51(Pt 2): 127-136, indexed in Pubmed: 17103809.

9. Degirmenci B, Haktanir A, Acar M, et al. Agenesis of sphenoid sinus: three cases. Surg Radiol Anat. 2005; 27(4): 351-353, doi: 10.1007/s00276-005-0336-5, indexed in Pubmed: 16200385.

10. Earwaker J. Anatomic variants in sinonasal CT. Radiographics. 1993; 13(2): 381-415, doi: 10.1148/radiographics.13.2.8460226, indexed in Pubmed: 8460226.

11. ELKammash T, Enaba M, Awadalla A. Variability in sphenoid sinus pneumatization and its impact upon reduction of complications following sellar region surgeries. Egypt J Radiol Nucl Med. 2014; 45(3): 705-714, doi: 10.1016/j. ejrnm.2014.04.020.

12. Elwany S, Elsaeid I, Thabet H. Endoscopic anatomy of the sphenoid sinus. J Laryngol Otol. 1999; 113(2): 122-126, doi: 10.1017/s0022215100143361, indexed in Pubmed: 10396560.

13. Elwany $S$, Yacout $Y M$, Talaat $M$, et al. Surgical anatomy of the sphenoid sinus. J Laryngol Otol. 1983; 97(3): 227-241, doi: 10.1017/s0022215100094056, indexed in Pubmed: 6833847.

14. Eryilmaz A, Ozeri C, Bayiz U, et al. Functional endoscopic sinus surgery (FESS). Turk J Med Res. 1993; 11(5): 221-223.

15. Haetinger RG, Navarro JAC, Liberti EA. Basilar expansion of the human sphenoidal sinus: an integrated anatomical and computerized tomography study. Eur Radiol. 2006; 16(9): 
2092-2099, doi: 10.1007/s00330-006-0208-3, indexed in Pubmed: 16642328.

16. Hamid O, El Fiky L, Hassan O, et al. Anatomic variations of the sphenoid sinus and their impact on trans-sphenoid pituitary surgery. Skull Base. 2008; 18(1): 9-15, doi: 10.1055/ s-2007-992764, indexed in Pubmed: 18592020.

17. Heskova G, Mellova $Y$, Holomanova A, et al. Assessment of the relation of the optic nerve to the posterior ethmoid and sphenoid sinuses by computed tomography. Biomed Pap Med Fac Univ Palacky Olomouc Czech Repub. 2009; 153(2): 149-152, doi: 10.5507/bp.2009.025, indexed in Pubmed: 19771141.

18. Hewaidi Gh, Omami Gm. Anatomic variation of sphenoid sinus and related structures in libyan population: CT scan study. Libyan J Med. 2008; 3(3): 128-133, doi: 10.4176/080307, indexed in Pubmed: 21499453.

19. Idowu OE, Balogun BO, Okoli CA. Dimensions, septation, and pattern of pneumatization of the sphenoidal sinus. Folia Morphol. 2009; 68(4): 228-232, indexed in Pubmed: 19950072.

20. Jaworek-Troć J, Iwanaga J, Chrzan R, et al. Anatomical variations of the main septum of the sphenoidal sinus and its importance during transsphenoidal approaches to the sella turcica. Transl Res Anat. 2020; 21: 100079, doi: 10.1016/j.tria.2020.100079.

21. Jaworek-Troć J, Zarzecki M, Bonczar A, et al. Sphenoid bone and its sinus - anatomo-clinical review of the literature including application to FESS. Folia Med Cracov. 2019; 59(2): 45-59, indexed in Pubmed: 31659348.

22. Jaworek-Troć J, Zarzecki M, Mróz I, et al. The total number of septa and antra in the sphenoid sinuses - evaluation before the FESS. Folia Med Cracov. 2018; 58(3): 67-81, doi: 10.24425/ fmc.2018.125073, indexed in Pubmed: 30521512.

23. Jaworek-Troć J, Zarzecki M, Zamojska I, et al. The dimensions of the sphenoid sinuses: evaluation before the functional endoscopic sinus surgery. Folia Morphol. 2021; 80(2): 275-282, doi: 10.5603/FM.a2020.0059, indexed in Pubmed: 32488857 .

24. Kajoak SA, Ayad CE, Najmeldeen M, et al. Computerized tomography morphometric analysis of the sphenoid sinus and related structures in sudanese population. Glo/ Adv Res J Med Med Sci. 2014; 3(7): 160-167.

25. Kantarci M, Karasen RM, Alper F, et al. Remarkable anatomic variations in paranasal sinus region and their clinical importance. Eur J Radiol. 2004; 50(3): 296-302, doi: 10.1016/j.ejrad.2003.08.012, indexed in Pubmed: 15145491

26. Kayalioglu G, Erturk M, Varol T. Variations in sphenoid sinus anatomy with special emphasis on pneumatization and endoscopic anatomic distances. Neurosciences (Riyadh). 2005; 10(1): 79-84, indexed in Pubmed: 22473192.

27. Kazkayasi M, Karadeniz Y, Arikan OK. Anatomic variations of the sphenoid sinus on computed tomography. Rhinology. 2005; 43(2): 109-114, indexed in Pubmed: 16008065.

28. Keast A, Yelavich S, Dawes $P$, et al. Anatomical variations of the paranasal sinuses in Polynesian and New Zealand European computerized tomography scans. Otolaryngol Head Neck Surg. 2008; 139(2): 216-221, doi: 10.1016/j. otohns.2008.05.014, indexed in Pubmed: 18656718.

29. Kikuchi R, Toda M, Tomita T, et al. Analysis of sphenoid sinus lateral pneumatization for endonasal endoscopic surgery. Surg Neurol Int. 2015; 6: 166, doi: 10.4103/21527806.168313, indexed in Pubmed: 26962467.

30. Krzeski A, Osuch-Wójcikiewicz E, Szwedowicz $P$, et al. Chirurgia endoskopowa $w$ leczeniu guzów jam nosa i zatok przynosowych. Mag ORL. 2004; 3(3): 79-84.

31. Lewin JS, Curtin HD, Eelkema E, et al. Benign expansile lesions of the sphenoid sinus: differentiation from normal asymmetry of the lateral recesses. Am J Neuroradiol. 1999; 20(3): 461-466, indexed in Pubmed: 10219412.

32. Li Y, Sun J, Zhu X, et al. Study of the relationship between sphenoid sinus volume and protrusions in the sphenoid sinus. Forensic Med Anat Res. 2014; 02(01): 2-7, doi: 10.4236/fmar.2014.21002.

33. Lupascu M, Comsa G, Zainea V. Anatomical variations of the sphenoid sinus: a study of 200 cases. ARS Medica Tomitana. 2014; 20(2): 57-62, doi: 10.2478/arsm-2014-0011.

34. Mafee MF, Chow JM, Meyers R. Functional endoscopic sinus surgery: anatomy, CT screening, indications, and complications. Am J Roentgenol. 1993; 160(4): 735-744, doi: 10.2214/ ajr.160.4.8456654, indexed in Pubmed: 8456654.

35. Mutlu C, Unlu HH, Goktan C, et al. Radiologic anatomy of the sphenoid sinus for intranasal surgery. Rhinology. 2001; 39(3): 128-132, indexed in Pubmed: 11721501.

36. Ota N, Tanikawa R, Miyazaki T, et al. Surgical microanatomy of the anterior clinoid process for paraclinoid aneurysm surgery and efficient modification of extradural anterior clinoidectomy. World Neurosurg. 2015; 83(4): 635-643, doi: 10.1016/j. wneu.2014.12.014, indexed in Pubmed: 25527880.

37. Sabaté J, Carmona A, Catalina-Herrera CJ, et al. Anatomical variations in the human paranasal sinus region studied by CT. J Anat. 2000; 197 (Pt 2): 221-227, doi: 10.1046/j.14697580.2000.19720221.x, indexed in Pubmed: 11005714.

38. Peele JC. Unusual anatomical variations of the sphenoid sinuses. Laryngoscope. 1957; 67(3): 208-237, doi: 10.1288/00005537-195703000-00004, indexed in Pubmed: 13417674.

39. Santhana Lakshmi R, Gugapriya S, Vinay Kumar NT, et al. Positional variation of optic nerve in relation to sphenoid sinuses and its association with pneumatisation of anterior clinoid process: a radiological study. J Evid Based Med Healthc. 2015; 2(32): 4719-4728, doi: 10.18410/jebmh/2015/663.

40. Sareen D, Agarwal AK, Kaul JM, et al. Study of sphenoid sinus anatomy in relation to endoscopic surgery. Int J Morphol. 2005; 23(3), doi: 10.4067/s071795022005000300012.

41. Schlosser RJ, Bolger WE. Significance of empty sella in cerebrospinal fluid leaks. Otolaryngol Head Neck Surg. 2003; 128(1): 32-38, doi: 10.1067/mhn.2003.43, indexed in Pubmed: 12574756.

42. Shetty PG, Shroff MM, Fatterpekar GM, et al. A retrospective analysis of spontaneous sphenoid sinus fistula: MR and CT findings. Am J Neuroradiol. 2000; 21(2): 337-342, indexed in Pubmed: 10696020.

43. Sinha S, Shetty A, Nayak K. The morphology of Sella Turcica in individuals with different skeletal malocclusions: a cephalometric study. Trans Res Anat. 2020; 18: 100054, doi: 10.1016/j.tria.2019.100054.

44. Stecco A, Boccafoschi F, Falaschi Z, et al. Virtual dissection table in diagnosis and classification of Le Fort fractures: A retrospective study of feasibility. Trans Res Anat. 2020; 18: 100060, doi: 10.1016/j.tria.2019.100060. 
45. Štoković N, Trkulja V, Dumić-Čule I, et al. Sphenoid sinus types, dimensions and relationship with surrounding structures. Ann Anat. 2016; 203: 69-76, doi: 10.1016/j. aanat.2015.02.013, indexed in Pubmed: 25843780.

46. Tan HKK, Ong YK. Sphenoid sinus: an anatomic and endoscopic study in Asian cadavers. Clin Anat. 2007; 20(7): 745-750, doi: 10.1002/ca.20507, indexed in Pubmed: 17583590 .

47. Tchoyoson Li, Dillon WP, McDermott MW. Mucocele involving the anterior clinoid process: MR and CT findings. Am J Neuroradiol. 1999; 20(2): 287-290.

48. Terra ER, Guedes FR, Manzi FR, et al. Pneumatization of the sphenoid sinus. Dentomaxillofac Radiol. 2006; 35(1): 47-49, doi: $10.1259 / \mathrm{dmfr} / 55048928$, indexed in Pubmed: 16421265.

49. Tomovic S, Esmaeili A, Chan NJ, et al. High-resolution computed tomography analysis of variations of the sphenoid sinus. J Neurol Surg B Skull Base. 2013; 74(2): 82-90, doi: 10.1055/s-0033-1333619, indexed in Pubmed: 24436893.

50. Ulu MO, Aydin S, Kayhan A, et al. Surgical management of sphenoid sinus lateral recess cerebrospinal fluid leaks: a single neurosurgical center analysis of endoscopic endonasal minimal transpterygoid approach. World Neurosurg. 2018; 118: e473-e482, doi: 10.1016/j. wneu.2018.06.219, indexed in Pubmed: 29981913.
51. Unal B, Bademci G, Bilgili YK, et al. Risky anatomic variations of sphenoid sinus for surgery. Surg Radiol Anat. 2006; 28(2): 195-201, doi: 10.1007/s00276-005-0073-9, indexed in Pubmed: 16429266.

52. Vidić $B$. The postnatal development of the sphenoidal sinus and its spread into the dorsum sellae and posterior clinoid processes. Am J Roentgenol Radium Ther Nucl Med. 1968; 104(1): 177-183, doi: 10.2214/ajr.104.1.177, indexed in Pubmed: 5672763.

53. Wang J, Bidari S, Inoue K, et al. Extensions of the sphenoid sinus: a new classification. Neurosurgery. 2010; 66(4): 797-816, doi: 10.1227/01.NEU.0000367619.24800.B1, indexed in Pubmed: 20305499.

54. Woodworth BA, Prince A, Chiu AG, et al. Spontaneous CSF leaks: a paradigm for definitive repair and management of intracranial hypertension. Otolaryngol Head Neck Surg. 2008; 138(6): 715-720, doi: 10.1016/j. otohns.2008.02.010, indexed in Pubmed: 18503841.

55. Yonetsu K, Watanabe M, Nakamura T. Age-related expansion and reduction in aeration of the sphenoid sinus: volume assessment by helical CT scanning. Am J Neuroradiol. 2000; 21(1): 179-182, indexed in Pubmed: 10669247.

56. Yune HY, Holden RW, Smith JA. Normal variations and lesions of the sphenoid sinus. Am J Roentgenol Radium Ther Nucl Med. 1975; 124(1): 129-138, doi: 10.2214/ ajr.124.1.129, indexed in Pubmed: 167598. 